\title{
PERAN MODAL SOSIAL TERHADAP PRODUKTIVITAS PETANI JAMBU MERAH DI DESA WATUAGUNG KABUPATEN SEMARANG
}

\section{THE SOCIAL CAPITAL ROLE ON FARMER'S PRODUCTIVITY OF GUAVA IN WATUAGUNG VILLAGE SEMARANG REGENCY}

\author{
EFA ZUWANDASARI, LASMONO TRI SUNARYANTO* \\ Fakultas Pertanian dan Bisnis, Universitas Kristen Satya Wacana \\ J1. Diponegoro 52-60 Salatiga 50711, Jawa Tengah-Indonesia \\ *E-mail: lasmono.jurnal@gmail.com
}

\begin{abstract}
ABSTRAK
Tujuan dari penelitian ini adalah (1) Menganalisis modal sosial yang dimiliki petani jambu merah di Desa Watuagung yang dilihat dari komponen modal sosial kepercayaan, norma, jaringan. (2) Mengetahui perbandingan modal sosial petani jambu merah lahan sempit, sedang, dan luas di Desa Watuagung. (3) Mengetahui peran modal sosial petani terhadap produktivitas petani jambu merah di Desa Watuagung. Penelitian dilakukan pada bulan Juli 2020-November 2020 di Desa Watuagung Kabupaten Semarang. Penelitian dilakukan dengan metode kualitatif komparatif untuk membandingkan peran modal sosial terhadap produktivitas petani jambu merah pada petani lahan sempit, sedang, dan luas. Unit yang diamati adalah peran modal sosial kepercayaan, norma dan jaringan. Teknik pengumpulan data dengan observasi dan wawancara. Hasil penelitian menunjukan bahwa: Modal sosial kepercayaan, norma, dan jaringan dimiliki oleh petani jambu merah di Desa Watuagung. Modal sosial sosial kepercayaan dan norma yang dimiliki petani jambu merah lahan sempit, sedang, dan luas adalah sama. Perbedaanya adalah jaringan petani lahan sempit lebih sedikit sedangkan petani lahan sedang dan luas lebih banyak. Petani lahan sempit memiliki modal sosial yang rendah. Petani lahan sedang dan luas memiliki modal sosial tinggi. Peran modal sosial terhadap produktivitas petani jambu merah di Desa Watuagung adalah semakin tinggi modal sosial yang dimiliki petani maka produktivitasnya semakin tinggi.
\end{abstract}

Kata Kunci: Jambu Merah, Modal Sosial, Produktivitas, Usahatani

\begin{abstract}
The objectives of this study are (1) Analyze the social capital owned by guava farmers in Watuagung Village which can be seen from the social capital components of trust, norms, and networks. (2) Knowing the comparison of social capital of guava farmers on narrow, medium, and wide land in Watuagung Village. (3) Knowing the role of farmers' social capital on the productivity of guava farmers in Watuagung Village. The research was conducted in July 2020-November 2020 in Watuagung Village, Semarang Regency. The study was conducted using a comparative qualitative method to compare the role of social capital on the productivity of guava farmers on small, medium, and large land farmers. The unit observed is the role of social capital trust, norms and networks. Data collection techniques by observation and interviews. The results showed that: The social capital of trust, norms, and networks were owned by guava farmers in Watuagung Village. Social capital, social beliefs and norms owned by guava farmers in narrow, medium, and wide land are the same. The difference is that the network of small land farmers is less while the medium and large land farmers are more. Smallholder farmers have low social capital. Medium and large land farmers have high social capital. The role of social capital on the productivity of guava farmers in Watuagung Village is that the higher the social capital owned by the farmers, the higher the productivity.
\end{abstract}

Keywords: Guava, Social Capital, Productivity, Farming 


\section{PENDAHULUAN}

Pandemi Covid-19 membuat kesadaran hidup sehat menjadi salah satu tren bagi masyarakat Indonesia. Tren hidup sehat dapat dilakukan dengan cara Gerakan Masyarakat Hidup Sehat (GERMAS) melalui olahraga secara teratur, istirahat yang cukup, makan makanan dengan gizi seimbang, menjaga kebersihan lingkungan, tidak merokok, tidak minum minuman beralkohol, selalu berpikir positif dan rajin mengonsumsi sayur dan buah segar. Jambu merah (Psidium guajava L.) merupakan salah satu buah yang dapat menjadi pilihan untuk dikonsumsi setiap hari dan mengandung vitamin C (Kemenkes 2017).

Produktivitas jambu merah di Kabupaten Semarang pada tahun 2017 sebesar 0,72 ku/ha (BPS 2019). Tingkat produktivitas ini masih di bawah rata-rata produktivitas jambu merah di Jawa Tengah yang besarnya $0,81 \mathrm{ku} / \mathrm{ha}$ (BPS 2019). Produktivitas jambu merah sejalan dengan produktivitas petani. Produkti-vitas petani merupakan suatu sikap dan mental yang selalu berusaha dan memiliki pandangan bahwa hari ini harus lebih baik dari hari kemarin dan hari esok juga harus lebih baik dengan meng-gunakan segala kemampuan yang dimiliki. Produktivitas petani tidak terlepas dari modal sosial yang terdapat pada lingkungan petani
Produktivitas petani tidak terlepas dari modal sosial yang terdapat pada lingkungan petani. Petani yang berkembang memiliki lingkungan modal sosial yang mampu meningkatkan pengetahuan dan wawasan petani (Harahap and Herman 2018).

Dalam penelitian Wulandari, Wijaya, and Zuber (2018) berpendapat bahwa modal sosial merupakan salah satu faktor yang dapat meningkatkan produktivitas. Modal sosial merupakan aset yang dapat terbentuk dan tumbuh dalam diri seseorang sebagai hasil dari cara bersosialisasi yang baik. Modal sosial adalah rangkaian nilai atau norma tidak resmi yang dimiliki anggota dalam suatu kelompok sehingga memungkinkan terjadinya kerjasama. Modal sosial akan memberikan kemudahan akses informasi, menyelesaikan masalah, membentuk solidaritas dan membangun partisipasi (Hamsah 2017).

Modal sosial merupakan bagian dari kehidupan sosial yang didalamnya terdapat tiga komponen utama yaitu kepercayaan (trust), norma (norm), dan jaringan (network). Kepercayaan meru-pakan hubungan yang menguntung-kan antara dua orang atau lebih yang didalam-nya terdapat maksud dan harapan yang dilakukan melalui interaksi sosial. Norma atau nilai merupakan suatu aturan atau 
pedoman perilaku yang berperan penting untuk mengontrol bentuk perilaku. Sedangkan jaringan adalah kemampuan seseorang untuk melibatkan diri dalam suatu kelompok atau jaringan yang teratur dan konsisten sehingga mem-peroleh keuntungan dan hubungan timbal balik. Melalui jaringan akan lebih mudah memperoleh informasi dan komunikasi yang menguntungkan (Field 2010).

Usahatani jambu merah yang berlangsung di Watuagung merupakan usahatani milik petani setempat yang masih kental dengan adanya gotong royong, ritual leluhur, dan adat istiadat. Hal ini membuktikan bahwa modal sosial dimiliki petani jambu merah di Desa Watuagung. Oleh karena itu, penelitian ini bertujuan untuk menganalisis modal sosial yang dimiliki petani, mengetahui perbandingan modal sosial petani lahan sempit, sedang, dan luas dan mengetahui peran modal sosial petani terhadap produktivitas petani jambu merah di Desa Watuagung.

\section{METODE PENELITIAN}

Penelitian dilakukan pada bulan Juni 2020-November 2020 di Desa Watuagung Kabupaten Semarang. Pemilihan lokasi penelitian dipilih secara sengaja (purposive), dengan pertim-bangan bahwa di desa tersebut terdapat petani jambu merah dan mencerminkan adanya modal sosial yang dimiliki petani. Penelitian ini menggunakan metode kua-litatif komparatif untuk memperoleh persamaan atau perbedaan peran modal sosial petani lahan sempit, sedang, dan luas terhadap produktivitas petani jambu merah di Desa Watuagung.

Teknik pengumpulan data yang digunakan dalam penelitian ini adalah observasi dan wawancara. Data yang digunakan dalam penelitian ini adalah data primer dan data sekunder. Data primer diperoleh langsung dari partisipan dan Key Informant. Partisipan yaitu 3 petani jambu merah masing-masing dengan lahan sempit $\left(800 \mathrm{~m}^{2}\right)$, lahan sedang $\left(4000 \mathrm{~m}^{2}\right)$, dan lahan luas $\left(10000 \mathrm{~m}^{2}\right)$. Key Informant yaitu pelopor penanaman jambu. Data sekunder diperoleh melalui studi pustaka.

Tahapan analisis data kualitatif dilakukan menurut (Miles and Huberman 2009), yaitu:

\section{Koleksi Data}

Koleksi data merupakan proses merekam semua proses wawancara yang dilakukan, kemudian hasil wawancara yang telah diperoleh ditranskripsikan.

2. Reduksi Data

Reduksi data adalah proses menggabungkan dan menyeragamkan segala bentuk data yang relevan menjadi 
suatu bentuk tulisan yang akhirnya akan dianalisis. Reduksi data dilakukan dengan cara meringkas data, coding dan menelusuri tema.

3. Penyajian data

Penyajian data yaitu menyajikan data yang sudah diperoleh dari hasil wawancara menjadi hasil penelitian yang ditampilkan dalam bentuk teks naratif.

4. Penarikan Kesimpulan

Kesimpulan merupakan tahap terakhir yang dilakukan untuk memverifikasi data. Kesimpulan mengarah pada jawaban dari pertanyaan panduan wawancara dan merupakan jawaban tentang "apa" dan "bagaimana" data yang ditemukan di lapangan.

\section{HASIL DAN PEMBAHASAN}

\section{Gambaran Umum Partisipan dan Key}

\section{Informant}

Penelitian menggunakan 3 Partisipan dan 1 Key Informant. Partisipan dipilih sesuai kategori lahan dan petani jambu yang berdampak di Desa Watuagung. Partisipan tersebut adalah Mbak Mitar sebagai partisipan kategori lahan rendah sekaligus istri dari ketua kelompok tani Sumber Rezeki, Mbak Erna kategori lahan sedang dan dikenal sebagai pengepul jambu bagi petani lain, dan Pak Giyarto sebagai partisipan lahan luas dan orang yang cukup disegani di Dusun Nalen Watuagung. Key Informant adalah Pak Lami orang yang pertama kali berinisiatif menyewakan lahannya untuk ditanami jambu, orang dijadikan guru dalam usahatani jambu dan menjadi pelopor/penggerak penanaman jambu.

Tabel 1. Karakteristik Partisipan dan Key Informant

\begin{tabular}{lccc}
\hline Nama & $\begin{array}{c}\text { Usia } \\
(\mathbf{t h n})\end{array}$ & $\begin{array}{c}\text { Luas } \\
\text { Lahan } \\
\left(\mathbf{m}^{\mathbf{2}}\right)\end{array}$ & Ket. \\
\hline $\begin{array}{l}\text { Sasmitar } \\
\text { (Mbak Mitar) }\end{array}$ & 47 & 800 & $\begin{array}{c}\text { Partisipan 1 } \\
\text { (P1) }\end{array}$ \\
\hline $\begin{array}{l}\text { Ernawati } \\
\text { (Mbak Erna) }\end{array}$ & 40 & 4000 & $\begin{array}{c}\text { Partisipan 2 } \\
\text { (P2) }\end{array}$ \\
\hline $\begin{array}{l}\text { Sugiyarto } \\
\text { (Pak Giyarto) }\end{array}$ & 54 & 10000 & $\begin{array}{c}\text { Partisipan 3 } \\
\text { (P3) }\end{array}$ \\
\hline $\begin{array}{l}\text { Lami } \\
\text { (Pak Lami) }\end{array}$ & 67 & 5000 & $\begin{array}{c}\text { Key } \\
\text { Informant } \\
\text { (KI) }\end{array}$ \\
\hline
\end{tabular}

\section{Gambaran Umum Lokasi Penelitian}

Watuagung merupakan Desa yang terletak di Kecamatan Tuntang Kabu-paten Semarang. Nama Watuagung sendiri diambil dari Bahasa Jawa yaitu "Watu" yang berarti Batu dan "Agung" yang berarti Besar. Desa Watuagung dibagi menjadi 8 dusun.

Nalen merupakan salah satu dusun yang memiliki lahan pertanian yang cukup luas dan digunakan untuk melakukan kegiatan pertanian. Komo-ditas yang ditanam berupa tanaman pangan padi. Pak Lami yang merasa bahwa tanaman padi kurang meng-hasilkan dan membutuhkan tenaga yang lebih untuk merawatnya. 
Sekitar tahun 2008 Pak Lami berinisiatif menyewakan lahan miliknya. Pada awalnya tanah akan disewa untuk ditanami sengon, tetapi banyak warga sekitar yang menolak. Akhirnya tanah milik Pak Lami di sewakan dan ditanami jambu merah oleh penyewa.

"Iyo,terutama pas awal raono pendukungan. Seko ideku tak kontrakkke. Tanahku men kerumat nko mburine ono hasile. Dadi entek kontrake tinggal. Warga sini tidak menolak. Kalo sengon pada tidak setuju. terus yo keluarga tetangga do melu-melu." (KI)

(Iya, terutama saat tidak ada yang mendukung. Dari ideku untuk menyewakan lahan, tanahku menjadi terawat dan memberi hasil. Setelah habis masa sewa selesai. Warga sini tidak menolak. Kalau sengon pada tidak setuju. Kemudian keluarga dan tetangga ikutan)

$$
\text { Semenjak tanah Pak Lami }
$$

disewakan, warga sekitar mulai penasaran.

Mereka berpikir bahwa jambu sangat menghasilkan. Jika jambu tidak memiliki potensi yang bagus maka tidak mungkin ada orang yang berani menyewa lahan untuk budidaya jambu. Salah satu warga yaitu Pak Giyarto mulai tertarik menanam jambu dan menjadi salah satu warga asli Watu-agung yang pertama kali menanam jambu.

"Jambu merah kan awal tanam kui sebelah dikontrak tiang. Terus dee neng kene kontrak, omah kontrak, lahan kontrak kok wani nandur jambu. Terus aku dewe ndue nggon kok ra coba. Terus dee nanam aku minta beberapa pohon aku melu nanam sekitar 3 uwit ya sekitar rumah iki. awalane kan ngene iki kan sawah dilanda kekeringan terus sumber air digowo neng pemukiman, terus kekurangan air. Bingung yo kui awal rekoso gawe untung. Dadi nandur jambu kui." (P3)

(Awal penanaman jambu merah adalah lahan sebelah disewa oleh orang. Awal mula jambu merah itu dari Sukorejo Kendal. Mereka disini sewa, lahan sewa, rumah sewa kok berani menanam jambu. Saya sendiri punya lahan kok tidak mencoba. Akhirnya mereka menanam aku minta beberapa sekitar 3 pohon yang ditanam disekitar rumah ini. Awalnya disini kan sawah dan dilanda kekeringan karena sumber mata air dialirkan ke pemukiman. Bingung dan kesusahan jadi memutuskan menanam jambu)

Setelah lahan Pak Lami habis masa sewa sekitar 5 tahun dan tidak diperpanjang, Pak Lami dan Pak Giyarto menjadi panutan warga sekitar menanam jambu. Sampai saat ini, sekitar 30 petani keluarga dan non keluarga Pak Lami beralih dari menanam padi menjadi jambu merah. Jambu merah lebih menghasilkan, perawatanya lebih mudah dan tidak memerlukan banyak air, sehingga banyak petani yang beralih menanam jambu daripada padi.

\section{Bentuk Modal Sosial}

Menurut Woolcock (dalam Field 2010) modal sosial terbagi menjadi tiga bentuk yang merupakan wujud energi untuk memaksimalkan potensi modal lainya. Bentuk modal sosial tersebut meliputi perekat/pengikat (bonding social capital), penyambung/menjembatani (bridging social capital) dan 
koneksi/akses (linking social capital). Bonding merupakan suatu ikatan yang yang mengalami situasi dan perasaan yang sama, seperti keluarga, sahabat, dan tetangga. Bridging hampir mirip dengan bonding hanya saja ikatan yang terbentuk lebih longgar, seperti ikatan individu dengan rekan kerja dan teman jauh. Linking social capital adalah tipe yang menjangkau individu dari kondisi berbeda, status sosial berbeda, dan latar belakang yang berbeda pula.

Keluarga petani selalu membantu dan memberi motivasi kepada petani untuk semangat menjalankan usahatani. Mbak Mitar didukung oleh Bapaknya yang dulu petani padi, Mbak Erna didukung suami dan Pak Giyarto didukung istrinya. Bentuk dukungan tersebut bermacam-macam mulai dari membantu mencari air, membantu menyiram dan membantu memanen dan menjual jambunya. Hal tersebut di konfirmasi Pak Lami sebagai berikut:

"Yo dukung, ra ketong ngewangi lep opo panen. pokoke yo ngewangi opo neh nak adol." (KI)

(Ya didukung, meskipun hanya membantu menyiram atau panen. Yang jelas membantu. Apalagi saat menjualnya)

Bridging dalam usahatani jambu merah ada pada hubungan antara partisipas dan rekan kerjanya. Baik rekan kerja berupa pembeli, reseller, ataupun pekerja.
Bentuk modal sosial bridging tersebut membuat petani lebih mudah menjalankan usahataninya karena bisa menciptakan hubungan dengan pembeli, reseller dan distributor.

Linking social capital tidak ditemui pada 3 petani. Hal itu dikarenakan petani secara mandiri menanam jambu dan mengandalkan pengalaman Pak Lami. Pihak yang menanam modal atau yang lebih tinggi tidak ada. Modal diperoleh dari uang tabungan petani. Izin menjalankan usahatani juga tidak ada. Selagi lahan milik sendiri dan tetangga mempersilahkan maka bebas. Berikut penjelasanya Mbak Mitar:

"Gak ada, kalo modal sendiri. Wong gone sitik yo modale sitik. Mung aku raiso masarke, raiso neng pasar dewe. Paling yo pesenan, tak WA butuh jambu ra mbak gitu. "(P1)

(Tidak ada, modal sendiri. Lahannya sedikit ya modalnya sedikit. Yang jelas aku tidak bisa memasarkan sendiri. Paling aku WA butuh jambu tidak)

Mbak Erna dan Pak Giyarto juga menggunakan tabunganya sendiri dalam menanam jambu merah.

"Modal sendiri, karena emang punya modal daripada nanti mengembalikan ya lebih baik milik sendiri." (P2)

"Modal sendiri." (P3)

\section{Komponen Modal Sosial}

Modal sosial merupakan suatu kesatuan dari sumber yang potensial dan terbaru untuk memperjuangkan tujuan bersama dalam suatu kelompok atau 
organisasi dengan cara bekerjasama.

Kerjasama dapat terjalin dengan baik apabila terdapat tanggung jawab, komitmen, kejujuran, timbal balik yang sesuai dan diharapkan (Supono 2011).

\section{Kepercayaan}

Kepercayaan adalah rasa aman karena tidak saling curiga dalam menjalin kerjasama dengan sesama (Alfiasari, Darmawan, and Martianto 2009). Petani kategori lahan sempit, sedang, dan luas memiliki gambaran kepercayaan yang berbeda-beda. Mbak Mitar percaya dengan rekan kerjanya yang sudah dari awal bekerjasama dan tidak takut ditipu karena rezeki sudah ada yang mengatur.

"Yo ngono ki yo percoyo, nyante. Wong yo tonggone dewe. Percoyo wae lah mbak, Kadang bayar raono susuk yowes gowonen sek. Yo dari awal wae, nak ono jambu, ditawari gelem yo monggo. Pokoke rezeki wes ono seng ngatur. (P1) (Ya percaya santai sama tetangga sendiri. Percaya ajalah mbak. Kadang bayar tidak ada kembalian yaudah silahkan dibawa dulu. Ya dari awal kalau ada jambu dan ditawari mau)

Mbak Erna memiliki rasa kepercayaan kepada rekan kerjanya 100\% dan selalu memberi berbagai insentif dan bonus agar rekan kerjanya tetap nyaman bekerja dengan Mbak Erna. Berikut penuturannya:

" $100 \%$ Karena udah saya percayakan sama rekan itu apapun yang dia lakukan pokoknya saya percaya emang orangnya jujur setia. Kerjanya gak di tunggu gak diawasi, kalau saya ngasih misalkan plastik
Itu harus setiap bungkus dari jam 7 sampai jam 12 Harus habis. begini dia juga habis Kok nggak dibuang nggak diapain enggak diumpetke gitu enggak. Pokoknya habis untuk bungkusin semua." (P2)

Sedangkan Pak Giyarto percaya 100\% kepada rekan kerjanya atas dasar bahwa mereka juga membutuhkan pekerjaan. Dalam menunjukan rasa percaya Pak Giyarto terhadap rekan kerja, pekerja tidak diawasi tetapi tetap diberi target.

\footnotetext{
"Ya 100\% percaya. Butoh nyambut gawe yo nyambut gawe. Ndelalah kok yo do percoyo, jadi saya itu belum pernah sampe seng tuku kui nonton timbangan. Dadi tak timbangi seko ngomah $25 \mathrm{~kg}$ yo $25 \mathrm{~kg}$. wes percoyo." (P3)

(Ya 100\% percaya. Butuh kerja ya kerja, untungnya pada percaya, jadi saya itu belum pernah sampai yang beli itu melihat hasil timbangan. Dari rumah sudah ditimbangi, $25 \mathrm{~kg}$ ya 25 sudah percaya)
}

\section{Norma}

Norma (norm) adalah kumpulan aturan dan pedoman untuk dapat dipatuhi oleh suatu kelompok sosial tertentu. Norma merupakan bagian dari modal sosial yang terbentuk dengan sendirinya melalui kebiasaan, tradisi, sejarah, tokoh kharismatik yang kemudian membentuk suatu tata cara/pedoman/aturan berperilaku (Fukuyama 2002). Mbak Mitar dalam menjalankan usahatani jambu merah sejauh ini tidak ada aturan tertulis melainkan kesadaran diri sendiri.

"Nak tertulis yo gak ada, tapi nak seko atiku dewe yo berusaha semaksimal mungkin misal nimbangi nak kurang yo 
ojo. Nak iso palah punjul. Misale jambu elek yo tak goleki sek, iki elek rasah wae. Nak gelem yo gowonen tak imbohke wae." (P1)

(Kalau tertulis tidak ada, tapi dari hatiku sendiri berusaha semaksimal mungkin kalau nimbang jangan kurang tapi lebih. Misalnya jambu jelek ya aku cari dulu, ini jelek tidak usah saja. Kalau mau ya bawa saja buat tambahan)

Mbak Erna tidak memiliki aturan tertulis terhadap rekan kerjanya dengan dasar kepercayaan yang dimiliki, tetapi Mbak Erna dan rekan memiliki suatu kebiasaan yang telah menjadi kese-pakatan bersama dan diketahui semua rekan kerjanya. Contohnya adalah jam kerja untuk mulai membungkus jambu atau mencangkul mulai dari jam 07.00 dan selesai jam 12.00. Jika berhalangan hadir maka harus izin atau konfirmasi terlebih dahulu.

"Tidak, saling percaya aja. Pulangnya jam 12 berangkat jam 7 pulang jam 12 kalau memang ada kepentingan ngomong." (P2)

Pak Giyarto juga tidak memiliki aturan baku, hanya mengikuti perkembangan dan kebiasaan yang ada di daerah sekitar. Jika ditempat Mbak Erna jam 07.00 berangkat dan jam 12.00 pulang, di tempat Pak Giyarto jam pulang ditentukan oleh Adzan. Jika jam 11 sudah terdengar tanda-tanda Adzan, maka sudah bisa pulang.

"Yo umume wong kerjo jam 7 kae mangkat, bejo bejone wong adzan jam 11 kae yo bali." (P3)
(Ya umumnya orang kerja, jam 7 berangkat, beruntung kalau jam 11 adzan ya pulang)

Setiap petani memiliki aturan sendiri-sendiri dan sesuai yang disampaikan oleh Key Informant. Aturan tersebut merupakan kebiasaan yang sudah disepakati bersama dan diketahui antara petani dan rekan kerja.

"Kui sak karepe seng ndue, neng biasane yo raono seng do buruh wes reti dewe dewe." (KI)

(Itu terserah yang punya. Biasanya tidak ada. Yang buruh sudah paham sendiri)

Selain aturan dalam menjalankan usahatani di Desa Watuagung juga ada Norma atau nilai adat budaya yang masih dilakukan warga dan sudah dilestarikan dari zaman dahulu. Nilai-nilai adat tersebut biasanya dilakukan satu tahun sekali seperti Wayang dan kegiatan punggahan. Sanksi dari melanggar norma juga ada, tetapi petani merasa jika melanggar norma tidak ada hukumannya. Berikut penuturan Key Informant:

"Yo bebas, hak asasi. paling yo sok di dendo nak ratau ngetok blas." (KI)

(Ya bebas, hak asasi, paling kalau tidak pernah terlihat di denda)

Dari ketiga Petani dan dikuatkan oleh Key Informant, semua mengatakan jika melanggar norma tidak ada sanksinya dan tergantung kesadaran diri masingmasing. Padahal rasa malu, dibicarakan tetangga, membayar iuran lebih, dan membayar denda tanpa disadari merupakan 
harga yang harus dibayar jika melanggar norma. Dapat dikatakan bahwa petani hanya memahami bahwa sanksi hanya berupa penjara/vonis didapat dari instansi pemerintah.

\section{Jaringan}

Jaringan merupakan pola koneksi suatu hubungan yang teratur, terorganisasi, konsisten, berlangsung lama dan terus menerus antara individu maupun kelompok (Lawang 2005). Kerjasama dapat terjalin dengan baik apabila terdapat tanggung jawab, komitmen, kejujuran, timbal balik dan proaktif yang sesuai dan diharapkan (Supono 2011). Dalam penelitian (Joo and Taejo Lim 2009) menyatakan bahwa seseorang yang memiliki kepribadian yang proaktif dalam mengerjakan tugas lebih inovatif, kreatif dan berkarakteristik dibandingkan seseorang yang pasif.

Mbak Mitar tidak bisa membawa jambunya sendiri ke Pasar karena ada pekerjaan sampingan di Balai Desa dan jika membawa ke pasar sendiri biaya transportasinya tidak sebanding dengan hasil penjualan jambu. Hal itu membuat Mbak Mitar menjual jambunya melalui perantara salah satunya Mbak Erna. Mbak Mitar mulai bekerjasama dengan Mbak Erna semenjak pertama kali panen jambu. Kerjasama tersebut sudah berlangsung sejak lama dan terus-menerus. Berikut penjelasanya:

"Yo dari awal wae, nak ono jambu, ditawari gelem yo monggo. Pokoke rezeki wes ono seng ngatur. "(P1)

(Ya dari awal saja, kalau ada jambu, ditawari mau ya silahkan. Rezeki sudah ada yang mengatur)

Pola jaringan Mbak Erna juga sudah berlangsung sejak mulai menanam jambu. Sebelum panen Mbak Erna sudah memiliki rekan kerja yang bertugas merawat lahan.

"Rekan kerja dulu sebelum berbuah suami, 2 tetangga yang membantu membungkus membersihkan rumput-rumput yang ada di bawah yang ada di sekitar pohon jambu serta membantu dalam pemupukan. Perempuan yang membungkus jambu waktu di pohon kalau yang laki-laki mencangkul sekitar pohon jambu dan yang memupuk." (P2)

Setelah berbuah, Mbak Erna bekerja sama dengan beberapa pengepul dan pembeli. Salah satunya yaitu segari.id Jakarta. Mbak Erna bekerjasama dengan segari.id untuk menyuplai jambu. Dalam melakukan kerja sama dengan segari.id, Mbak Erna bekerjasama dengan distributor yang memiliki peran menyalurkan jambu dan menyortir jambu sesuai permintaan.

Disisi lain, Pak Giyarto pernah berganti berganti rekan kerja. Pada awalnya Pak Giyarto mengandalkan reseller superindo. Karena terjadi masalah, uang pembayaran jambu sering tertunda dan lama-lama tidak dibayarkan. Pak Giyarto berinisiatif memperluas jaringannya mulai dari rumah ke rumah, 
agen buah, sampai pasar ke pasar dan sekarang sudah memiliki pembeli langganan di pusat oleh-oleh di Bandungan dan juga sebagai pemasok di wisata petik buah Bandungan.

"Dulu awale kan punya reseller superindo. Tapi aku terbentur neng masalah keuangan. De utang terus nggaduk. Terus aku stop tak iderke turut kampong. Terus ketemu gunung pati kan ono wisata petik buah. Ketemu seng jenenge Amir tak satori tapi suwe suwe yo gaduk. Terus alternative neng bandungan tempat wisata door to door nanya agen agen buah sg agak gede. Aku senenge jual opo anane. Nak minta bagus yo hargane beda. Nak ono seng jaluk apik yo hargane beda." (P3)

(Dulu awalnya punya reseller di superindo. Tapi aku terbentur di masalah keuangan Dia hutang dan tidak membayar. Terus aku stop dan keliling kampung dan sampai di Gunung Pati di wisata petik buah bertemu dengan Amir, Aku setori buah tetapi lamalama juga tidak bayar. Alternatifnya ke Bandungan ke tempat wisata, door to door, nanya agen buah yang agak besar. Aku suka jual apa adanya. Kalau minta bagus ya harganya beda)

\section{Produktivitas Petani Jambu Merah}

Produktivitas merupakan suatu sikap dan mental yang selalu berusaha dan memiliki pandangan bahwa mutu kehidupan hari ini harus lebih baik dari hari kemarin dan hari esok juga harus lebih baik dengan menggunakan segala kemampuan yang dimiliki (Sinungan 2018).

Produktivitas petani jambu merah di Desa Watuagung dapat dilihat dari kemauan petani menanam jambu, waktu yang diperlukan petani untuk berubah, perkembangan usahatani jambunya dan harga jual jambu.

Mbak Mitar mulai menanam jambu merah di tahun 2016 meskipun sudah diajak sejak tahun 2008. Mbak Mitar menjual jambu merahnya seharga Rp.5000/Kg.

"5 tahunan mbak, wes rodok suwe ya 2016. Kalo pas gak ada gini paling pol polan 5000. Nko rodok akeh 4000 ngono wae" (P1)

(5 tahunan mbak, sudah lumayan lama ya dari 2016. Kalau pas tidak ada ya maksimal 5.000. nanti agak banyak ya 4.000 begitu saja)

Mbak Erna menanam jambu barubaru ini sekitar tahun 2015. Mbak Erna menjual jambu merahnya sebesar Rp8.000,- per kilogramnya.

"Sejak tahun 2015. Ya sekarang tinggal perawatan jadi gak keluar banyak uang sama ini coba nanam jambu kristal. Sudah keliatan hasilnya." (P2)

"Ya gak pasti pas musim kemarau gini jambu sekitar Rp8.000 per kilo kalau musim panas musim yaitu musim hujan kan dia murah, Murahnya itu paling yo 3.0004 .000 per kilo." (P2)

Tahun 2008 sejak jambu merah pertama kali ditanam di Watuagung Pak Giyarto merupakan petani pertama yang menanam ditahun yang sama.

Mulaine yo sekitar tahun 2008. Apik yo bulan bulan ini sampai $11 \mathrm{rb} 12 \mathrm{rb}$. (P3) ("Mulainya sekitar tahun 2008. Bagus ya bulan-bulan ini sampai 11 rb 12 rb.") 
Peran Modal Sosial Terhadap

\section{Produktivitas Petani}

Modal sosial petani jambu baik lahan sempit, sedang, dan luas sangat diperlukan terhadap produktivitas petani jambu. Bentuk modal sosial bonding dan bridging berperan dalam meningkatkan produktivitas petani. Bonding, bridging, dan linking berperan memudahkan petani memperoleh informasi untuk meningkatkan produktivitas dan juga dengan adanya bantuan keluarga dan tetangga dapat membantu petani melakukan pekerjaanya, sehingga bisa selesai lebih cepat. Bantuan keluarga juga mengurangi Penggunaan tenaga kerja sehingga biaya yang dikeluarkan dapat diminimalkan.

Petani lahan sempit, sedang, dan luas memiliki modal sosial kepercayaan dan norma yang sama. Perbedaan modal sosial petani lahan sempit, sedang, dan luas adalah jaringan yang dimiliki. Petani yang memiliki modal sosial yang tinggi akan lebih mudah untuk meningkatkan produktivitas kerjanya daripada petani yang memiliki modal sosial yang rendah. Tinggi rendahnya modal sosial petani dapat dilihat dari dilihat dari luasnya komponen modal sosial yang dimiliki. Petani yang memiliki kepercayaan tinggi dan jaringan luas akan lebih mudah bekerjasama dengan orang lain. Petani yang memegang teguh aturan dan norma, akan paham cara menghargai orang lain dan tidak akan melanggar aturan yang ada.

Peran modal sosial terhadap produktivitas petani jambu merah di Desa Watuagung adalah semakin tinggi modal sosial yang dimiliki petani maka produktivitasnya semakin tinggi. Petani lahan sempit memiliki modal sosial yang rendah karena kurangnya jaringan dimiliki sehingga produktivitasnya juga rendah dilihat dari keinginan dan waktu petani untuk berubah membutuhkan waktu yang lama dan harga jual jambunya yang paling rendah. Petani lahan sedang dan luas memiliki lebih banyak jaringan sehingga modal sosial yang dimiliki tinggi dan produktivitasnya tinggi karena keinginan dan waktu yang diperlukan untuk berubah tidak lama. Harga jual jambu merah petani lahan sedang dan luas juga diatas harga jual pasaran. 
Tabel 2 Modal Sosial Petani Jambu Merah

\begin{tabular}{llll}
\hline $\begin{array}{c}\text { Komponen Modal } \\
\text { Sosial }\end{array}$ & \multicolumn{1}{c}{ Sempit } & \multicolumn{1}{c}{ Lahan } \\
\cline { 2 - 4 } Kepercayaan & $\begin{array}{l}\text { Percaya karena rezeki } \\
\text { sudah ada yang } \\
\text { mengatur }\end{array}$ & $\begin{array}{l}\text { 100\% percaya karena sudah } \\
\text { lama bekerjasama }\end{array}$ & $\begin{array}{l}\text { 100\% percaya karena } \\
\text { sama-sama butuh } \\
\text { pekerjaan }\end{array}$ \\
Norma & $\begin{array}{l}\text { Menaati norma } \\
\text { kesepakatan bersama }\end{array}$ & $\begin{array}{l}\text { Menaati norma kesepakatan } \\
\text { bersama }\end{array}$ & $\begin{array}{l}\text { Menaati norma } \\
\text { kesepakatan bersama }\end{array}$ \\
Jaringan & Pembeli Jambu & $\begin{array}{l}\text { Petani jambu lain, pembeli } \\
\text { jambu, distributor, Segari.id }\end{array}$ & $\begin{array}{l}\text { Reseller, pembeli jambu, } \\
\text { pasar buah, wisata petik } \\
\text { buah, pelanggan door to } \\
\text { door }\end{array}$ \\
\hline
\end{tabular}

\section{KESIMPULAN DAN SARAN}

\section{Kesimpulan}

Berdasarkan hasil penelitian dan pembahasan di atas, dapat ditarik kesimpulan sebagai berikut:

1. Modal sosial kepercayaan (trust), norma (norm), dan jaringan (network) dimiliki oleh petani jambu merah di Desa Watuagung.

2. Modal sosial sosial kepercayaan dan norma yang dimiliki petani jambu merah lahan sempit, sedang, dan luas di Desa Watuagung adalah sama. Perbedaanya adalah jaringan petani lahan sempit lebih sedikit sedangkan petani lahan sedang dan luas lebih banyak. Petani lahan sempit memiliki modal sosial yang rendah sedangkan petani lahan sedang dan luas memiliki modal sosial yang tinggi.
3. Keberadaan modal sosial berperan terhadap produktivitas petani jambu merah di Desa Watuagung. Semakin tinggi modal sosial yang dimiliki petani maka produktivitasnya semakin tinggi.

\section{Saran}

1. Petani lahan sempit bisa membawa jambunya langsung ke pasar, sehingga harga yang diterima sesuai harga pasar dan bukan harga pengepul. Petani menambah luas penanaman jambu pada lahan yang masih kosong.

2. Petani terus memperluas jaringan sehingga saat panen raya sudah tahu akan dijual kemana.

3. Hendaknya petani lebih menyadari bahwa dibicarakan tetangga, membayar denda, dan rasa malu yang muncul akibat melanggar norma adalah sanksi bagi mereka. 


\section{DAFTAR PUSTAKA}

Alfiasari, A. Hadi Darmawan, and D. Martianto. 2009. "Modal Sosial Dan Ketahanan Pangan Rumah Tangga Miskin Di Kecamatan Tanah Sareal Dan Kecamatan Bogor Timur, Kota Bogor.” Jurnal Sosiologi Pedesaan 3 (1): 126-52.

BPS. 2019. "Jumlah Tanaman Yang Menghasilkan Dan Produksi Buah Sayur Tahunan (BST).” https://jateng.bps.go.id/statictable/201 9/10/16/1765/jumlah-tanaman-yangmenghasilkan-dan-produksi-buahsayur-tahunan-bst-menurut-kabupatenkota-di-jawa-tengah-2017.html.

Field, John. 2010. Modal Sosial. Yogyakarta: Kreasi Wacana.

Fukuyama, Francis. 2002. The Great Disruption. Yogyakarta: Qalam.

Hamsah. 2017. Modal Sosial Dalam Makassar Tidak Rantasa. Makassar: MIB.

Harahap, Mailina, and Surna Herman. 2018. "Hubungan Modal Sosial Dengan Produktivitas Petani Sayur (Studi Kasus Pada Kelompok Tani Barokah Kelurahan Tanah Enam Ratus Kecamatan Medan Marelan)." Jurnal Agrium 21 (2): 157-65.

Joo, Baek Kyo, and Taejo Lim. 2009. "The Effect of Organizational Learning
Culture, Perceived Job Complexity, and Proactive Personality on Organizational Commitment and Intrinsic Motivation." Journal of Leadership \& Organizational Studies 16 (1): 48-60.

Kemenkes. 2017. "GERMAS - Gerakan Masyarakat Hidup Sehat." http://promkes.kemkes.go.id/germas.

Lawang, R. 2005. Kapital Sosial Dalam Perspektif Sosiologik. Depok: FISIP UI.

Miles, M. B., and A. M. Huberman. 2009. Analisis Data Kualitatif. Jakarta: UI Press.

Sinungan, Muchdarsyah. 2018. Produktivitas: Apa Dan Bagaimana. Jakarta: Bumi Aksara.

Supono, Boedyo. 2011. "Peranan Modal Sosial Dalam Implementasi Manajemen Dan Bisnis." Jurnal Ekonomi Dan Kewirausahaan 11 (1): 10-16.

Wulandari, Indah, Mahendra Wijaya, and Ahmad Zuber. 2018. "Peranan Modal Sosial Dalam Meningkatkan Produktivitas Kerjapeternak (Studi Kasus Pada Peternak Ayam Broiler Pola Kemitraan Di Desa Maliran Kecamatan Ponggok Kabupaten Blitar).” Jurnal Analisa Sosiologi 7 (110-126). 